\title{
The effect of climate conditions on inter-annual flowering variability monitored by pollen traps below the canopy in Draved Forest, Denmark
}

\author{
Anne Birgitte Nielsen · Peter Friis Møller • \\ Thomas Giesecke • Beth Stavngaard • \\ Sonia L. Fontana • Richard H. W. Bradshaw
}

Received: 18 January 2010/ Accepted: 8 March 2010

(C) The Author(s) 2010. This article is published with open access at Springerlink.com

\begin{abstract}
Since 1967 annual pollen deposition has been monitored in the semi-natural mixed deciduous woodland Draved Forest by the Geological Survey of Denmark. In this paper, we analyse the variability in pollen accumulation rates for the eight most common deciduous trees, and their relationships to monthly temperature and precipitation. High summer temperatures in the year before flowering have a positive effect on pollen deposition for several species. A positive correlation between temperatures during the flowering season and pollen accumulation rates is found for Fagus sylvatica, Quercus robur, Fraxinus excelsior and Corylus avellana. The amount of precipitation can have both positive and negative effects on pollen accumulation, depending on species and on time of year. Linear modelling showed that combinations of monthly climate parameters could explain between 10 and $80 \%$ of the variation observed in different species. There were marked differences in the time series of pollen accumulation and pollen/climate relationships for some species
\end{abstract}

Communicated by W. O. van der Knaap.

A. B. Nielsen $(\varangle)$. P. F. Møller · T. Giesecke ·

B. Stavngaard - R. H. W. Bradshaw

Geological Survey of Denmark and Greenland (GEUS),

Øster Voldgade 10, 1350 København K, Denmark

e-mail: anne-birgitte.nielsen@biologie.uni-goettingen.de

A. B. Nielsen - T. Giesecke - S. L. Fontana

Department of Palynology and Climate Dynamics,

Albrecht-von-Haller-Institute for Plant Sciences,

Georg-August-University, Untere Karspüle 2,

37073 Göttingen, Germany

R. H. W. Bradshaw

Department of Geography, University of Liverpool, Roxby

Building, Liverpool L69 7ZT, UK between traps within the forest related to the location of trees near the traps. This underlines the importance of using multiple traps in a region for this type of study. Time series analyses were used to test for cyclicity in pollen accumulation rates, which could be caused by resource limitations or internal biological factors. No significant autocorrelations were found, although Alnus glutinosa showed a tendency towards 3-year cyclicity. These results indicate that, with the possible exception of Alnus glutin$o s a$, temperature and precipitation are the main factors controlling the annual variability in pollen deposition of the trees in Draved Forest.

Keywords Pollen monitoring - Annual pollen accumulation rates $\cdot$ Temperature $\cdot$ Precipitation

\section{Introduction}

Studies of the temporal variability of pollen deposition using time series data from Tauber pollen traps (Tauber 1974) can be used to improve the interpretation of palynological data in several ways. For example, high resolution pollen analytical investigations use the influence of temperature on flowering, known from trap studies, to reconstruct past high frequency climate variability (Huusko and Hicks 2009; Kuoppamaa et al. 2009). Trap data may also aid the interpretation of pollen preserved in annually laminated sediments. The understanding of temporal variation in pollen deposition is important in the evaluation of moss samples, which may only contain 1 year of pollen deposition (Pardoe et al. 2010, this volume), and in contributing to the understanding of pollen-vegetation relationships (Andersen 1974). This knowledge can also be important for the interpretation of pollen diagrams as taphonomic effects may 
distort the signal. Moreover, analysing the variation in pollen production can provide insights into plant biology and helps in the forecast of airborne pollen that causes allergic reactions.

Pollen trap studies from different regions have shown that annual pollen accumulation rates (PAR) of different species vary greatly from year to year (e.g. Andersen 1974; Autio and Hicks 2004; van der Knaap et al. 2010, this volume). This can be related to variations in climate, vegetation dynamics, internal biological factors in the plants themselves or combinations of these factors. There are many ways in which temperature and precipitation may affect pollen deposition of different species. Daily pollen monitoring has shown that the timing of pollen release is related to weather conditions. For example, the onset and culmination of the pollen season of Betula is largely determined by temperature, more specifically accumulated growing degree hours (Rasmussen 2001). When observing the daily variations in pollen concentration in the air, there is a clear negative relationship with precipitation, as rain washes the pollen out of the atmosphere (Sommer and Rasmussen 2008). The relationship between climate and the total amount of pollen that is deposited over the year is more complicated, as this depends on many different factors. Biological cyclicity in the plants or resource limitations can dictate that a year with high pollen production is followed by a year with low production, even if the climate of that year is favourable (Andersen 1974). Apart from this, the production of pollen is often related to the growing conditions in the previous year, because the amount of pollen that will be produced is at least partly determined at the time when the flowers are formed, which for deciduous trees is the summer before flowering. The weather in the flowering season, on the other hand, can affect pollen release and dispersal. In northern Finland for example, annual pollen deposition of Pinus has been shown to depend on the July temperature of the previous year, when the flower buds are formed; on early spring temperature of the flowering year, where frost may damage the buds; and on weather conditions at the time of flowering (McCarroll et al. 2003).

To shed light on the questions outlined above, Svend Th. Andersen from the Geological Survey of Denmark, placed a number of pollen traps in 1967 in Draved Forest, a small, semi-natural woodland in southern Jutland, Denmark. This study is still ongoing and is the longest pollen trap series in existence. Andersen (1974) initially analysed the first 6 years of data, and later re-evaluated his conclusions based on 10 years of sampling (Andersen 1980). Looking at the first 6 years (1967-1972) there appeared to be a biennial rhythm in the flowering of Quercus, Betula and Fagus. Tilia also showed a biennial cycle, but was out of phase with the other taxa (Andersen 1974). However, after
10 years of observation (Andersen 1980) the biennial pattern had become less clear. In this paper we will revisit the questions of pollen accumulation of different deciduous tree species in relation to climate variables and cyclicity using 33 years of data, from 1970 to 2002 . The long series presents a unique opportunity to evaluate inter-annual fluctuations and the relationships to climatic variables in detail.

\section{Materials and methods}

Study site

Draved Forest is a 250 ha woodland in southern Jutland, $20 \mathrm{~km}$ from the North Sea, at $55^{\circ} 01^{\prime} \mathrm{N}, 8^{\circ} 58^{\prime} \mathrm{E}$ (Fig. 1), ca. $20 \mathrm{~m}$ above sea level. The substrate in the area is predominantly clayey till of Saalian age, covered in large

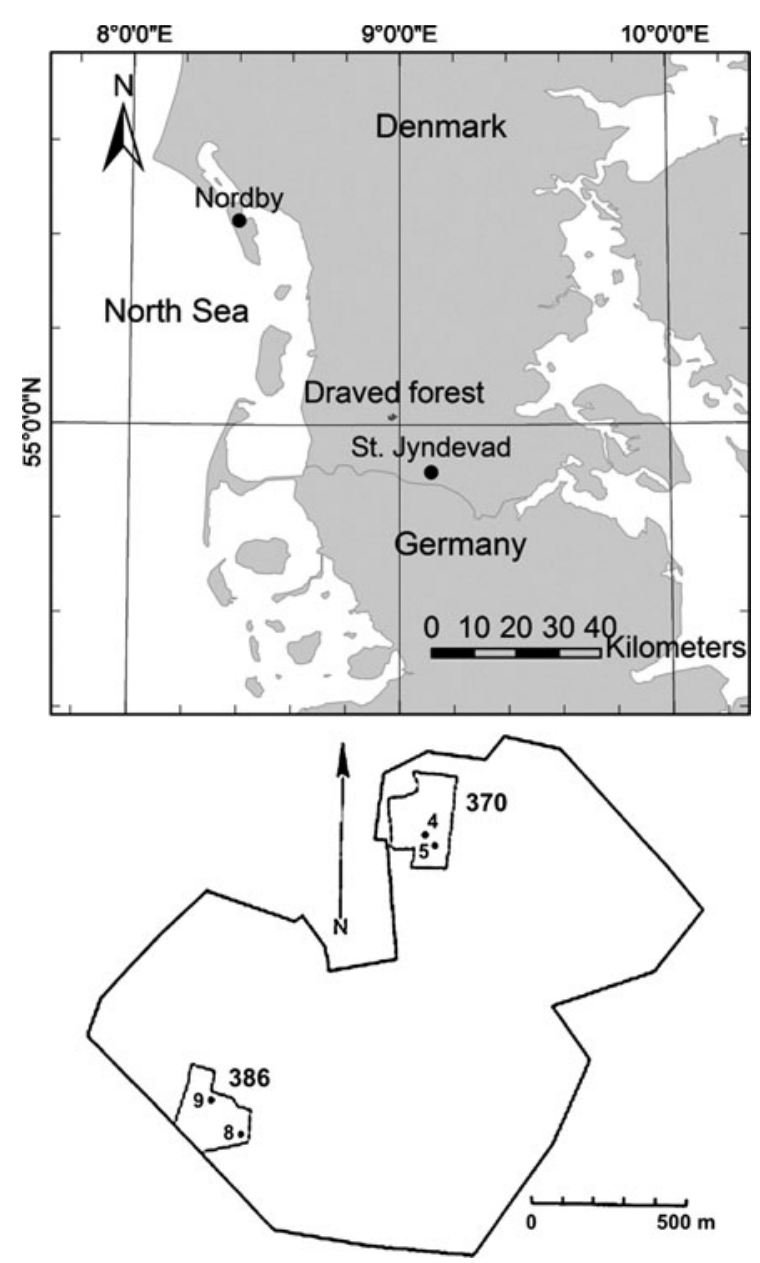

Fig. 1 Above: Map of south-western Denmark showing the location of Draved Forest (dark grey polygon) and the climate stations Nordby and Store Jyndevad (black circles). Below: Draved Forest, showing the locations of the studied forest sections and the four pollen traps used in this study (after Andersen 1974) 
parts by low, $5-100 \mathrm{~cm}$ thick sand dunes during the Weichselian (Aaby 1983; Møller and Bradshaw 2001). The thickest of these have in turn developed to podzol soils with a 5-60 cm thick humus layer during the Holocene (Iversen 1969), whereas elsewhere in the forest the soil consists of mull or humid mull (Wolf 2003). Quercus robur, Betula pubescens, Alnus glutinosa and Fagus sylvatica are common throughout Draved Forest, whereas Tilia cordata and Fraxinus excelsior occur more locally (Andersen 1980). Corylus avellana is found in the undergrowth in parts of the forest, while Ulmus glabra is rare in Draved Forest, occurring with a few fertile specimens in the north-western part of the Carlsberg enclosure. However, most of the fertile Ulmus trees died of Dutch elm disease during the late 1990s. Ilex aquifolium is also very common in Draved Forest, but as an insect pollinated species is not well represented in the pollen spectra from the traps. Other tree species in the forest include Populus tremula and Malus sylvestris. Sorbus aucuparia occurs sporadically as a pioneer. Crataegus laevigata and Viburnum opulus are part of the undergrowth on the mull soils, Ilex aquifolium and Frangula alnus on the podzol soils. The tree species will henceforth be referred to by genus names only.

Ecological and palaeoecological studies in Draved Forest were initiated by Johannes Iversen in 1947, and since then Draved has served as a study area for the Geological Survey of Denmark (DGU, later GEUS) (Møller 2000). In two forest sections with semi-natural stands, management was discontinued in 1948 (Carlsberg enclosure, Sect. 370) and 1952 (Lime enclosure, Sect. 386) (Wolf 2003). In 1999 the fences around the enclosures were removed and in 2000 all of Draved Forest became a non-intervention reserve (Møller 2000; Wolf 2003). In the late 1960s Andersen studied the relationship between pollen sedimentation in moss polsters and surrounding tree vegetation in the forest and calculated correction factors for tree pollen diagrams (Andersen 1967, 1970, 1973). At the same time he set up the pollen trap study (Andersen 1974).

Nine pollen traps were distributed in the Carlsberg and Lime enclosures so that each of the six most common tree species in the forest (Fagus, Quercus, Betula, Alnus, Tilia and Fraxinus) had a high representation around at least one trap. One of the traps was discontinued after a few years, but the remaining eight are still in operation. Crown cover within a $20 \mathrm{~m}$ radius of each trap was mapped in 1967 (Andersen 1974). In the current paper, we analyse the annual pollen accumulation rates of these six tree species and of Ulmus and Corylus, in four of the traps for the period 1970-2002. With the exception of Fraxinus, good representation is still maintained with the reduction to four traps used here. Alnus glutinosa and Fagus sylvatica occurred within $20 \mathrm{~m}$ of all four traps. Betula was dominant near trap 4 until around 1990 and also occurred at traps 5 and 9. Quercus occurred near traps 5 and 8 while Tilia was dominant near trap 9 and occurred near trap 8 . Fraxinus occurred near trap 5, although in low abundance. In the Carlsberg enclosure, where traps 4 and 5 are located, Corylus is common, especially near trap 4 and west and northwest of this trap.

Due to successional processes, there were some biomass changes during the 30 year period 1972-2001 (Bradshaw et al. 2005), including increases in Fagus and Quercus biomass and a marked decrease in the number of large Betula trees in both enclosures (Wolf 2003). Young Betula trees on the other hand, have expanded on areas outside the enclosures cleared of planted conifers during the period 1994-1999. The number of Alnus trees in the two forest sections has declined during the study period. In other parts of the forest, the tree number and basal area of Alnus has increased (Wolf 2003) in response to gradually wetter conditions as drainage ditches have been closed. However, these young Alnus had not yet begun to flower during the trapping period analysed here. Among the tree species not analysed here, Sorbus has expanded during the period, while Populus and Malus have declined.

\section{Pollen monitoring and climate data}

Annual pollen accumulation rates (PAR) have been monitored in eight Tauber traps (Tauber 1974) in Draved Forest since 1967 (Andersen 1974, 1980). The traps have an aerodynamic collar as described by Tauber (1974). The traps are elongated so that the mouth is placed $25 \mathrm{~cm}$ above the ground surface to prevent overflowing with rain water (Andersen 1974), and to be able to contain more water than the original $10 \mathrm{~cm}$ high traps (Tauber 1974). All traps are placed under the forest canopy. Svend Th. Andersen serviced the traps until 1994 and Peter Friis Møller since 1995. Until 1998 the traps were emptied twice a year and the counts combined, from 1999 they were emptied once a year. In 1998 the construction made of Perspex was renewed with a $21 \mathrm{PE}$ container, but with the same Tauber collar placed at the same height. In 2001 the traps were fenced to avoid pollution from foxes. The pollen analyses were made by C. Vang Nielsen, Svend Th. Andersen and Beth Stavngaard. From 1970 onwards, Lycopodium tablets (Stockmarr 1971) have been added to allow calculation of PAR. During the first 3 years, PAR estimation was based on different methods (Andersen 1974) and these years are therefore not included in the present study in which we analyse the pollen deposition of selected tree taxa in the traps in the 33-year period from 1970 to 2002. As some of the traps failed for one or more years for various reasons, including pollution by fox dung and perspex containers broken by frost, the analyses here are based on four traps 
which were functional for all 33 years. These were traps no. 4 and 5, placed ca. $40 \mathrm{~m}$ apart in forest Sect. 370 and traps 8 and 9, ca. $140 \mathrm{~m}$ apart in Sect. 386 (Fig. 1).

Pollen traps were in operation all year. In most years the final collection of the traps was between late January and early March. However, in some years the traps were collected later, in 1988 as late as 4th April. This means that for the early flowering species, especially Corylus but also occasionally Alnus, flowering had started at the time of collection. Thus, in some years part of the annual pollen production will have been assigned to the previous year. All four traps were used to calculate an average annual PAR for each taxon representing the entire forest.

Monthly temperature and precipitation data were obtained from the climate station at Nordby on the island of Fanø (Cappelen et al. 2008; Fig. 1). For this station, data were available for the entire pollen monitoring period. Another climate station at Store Jyndevad (Fig. 1) is located closer to Draved Forest, but temperature data from this station are only available from after 1987 (Laursen et al. 1999). For the period 1987-1997, monthly temperatures for the two stations were very closely correlated ( $r=0.995, P<0.001$ ) but generally about $1-2^{\circ} \mathrm{C}$ higher for the Nordby station, especially during the winter months. Hence, we used the data from the Nordby station for the entire period to avoid an artificial change in temperature at the time of transition between stations.

Precipitation is more spatially variable than temperature, although this effect is not too severe in South Jutland, due to the flat terrain. During the period 1961-1990 (Frich et al. 1997), precipitation data from the Store Jyndevad and Nordby stations were correlated ( $r=0.872, P<0.001)$. The mean monthly precipitation was slightly lower for Nordby $(65.3 \mathrm{~mm})$ than for Store Jyndevad $(71.5 \mathrm{~mm})$.

Winter climate in Denmark is influenced by the North Atlantic Oscillation (NAO), with winters with a positive NAO index being mild and wet, whereas winters with a negative index tend to be cold and dry (Danish Meteorological Institute 1999). To explore the effect of this on pollen production, the winter (December through March) index of the NAO, based on the difference of normalized sea level pressure (SLP) between Lisbon, Portugal and Stykkisholmur/Reykjavik, Island, was also analysed (NAO Index Data provided by the Climate Analysis Section, NCAR, Boulder, USA).

\section{Numerical analyses}

Correlation coefficients were calculated between PAR for the common trees and the monthly mean temperature and precipitation of the previous year and of the months of the flowering year until August. Annual and seasonal averages for temperature and annual and seasonal sums for precipitation were also analysed (Tables 1, 2). PAR were log transformed prior to analysis, as this made the data more normally distributed, while scatter plots showed that the relationships between PAR and the climate variables became more linear. The log transformation also minimised the effect of years with high PAR, which would otherwise have acted as outliers in the dataset. Correlations were computed between time series of individual traps in order to assess local differences in inter-annual variability between traps. The correlation between temperature and precipitation variables and PAR was repeated for individual traps and/or groups of traps for taxa that showed different patterns of variability. Due to the large number of comparisons, correlations that are only significant at the $P<0.05$ confidence level should be interpreted with some care. A Bonferonni correction would decrease the $P$-value required for significance to ca. 0.0001 , reducing the risk of type I error (i.e. accepting randomly occurring significant correlations) but would at the same time greatly increase the risk of type II error, i.e. missing true relationships (Perneger 1998), and was therefore not applied.

While correlation analysis gives an estimate of the marginal effects of each climatic variable, multiple linear regression analysis makes it possible to estimate unique effects of parameters, despite the fact that many of the climatic parameters are themselves correlated with each other. Using $\mathrm{R}$ version 2.9, linear models with a set of climate parameters as explanatory variables were fitted to the PAR data in the following way. An initial model was created for each pollen type, incorporating temperature and precipitation for the summer months (May to August) of the year before flowering, temperature and precipitation for the months during the flowering season for the species in question, together with any additional parameters found to have a statistically significant correlation with the pollen type in the correlation analysis. The rational was to include all variables that could potentially be expected to influence the PAR of the species in the initial model. It was not possible to include all temperature and precipitation variables in the initial model, as this would have exceeded the number of years of observation. The initial model for each species was analysed in a stepwise procedure using backward selection (Fox 2002), and the optimal model based on the Bayesian Information Criterion (BIC; Schwarz 1978) was determined.

Spectral analysis and autocorrelation were carried out to determine if the pollen accumulation of the different tree species showed any cyclic patterns. Before analysis, any linear trends in the PAR over the 33 years period were removed. The time series analyses were carried out using the programme PAST (Hammer et al. 2001). 
Table 1 Correlation coefficients between log annual PAR and average monthly and seasonal temperatures of the flowering year and the year before

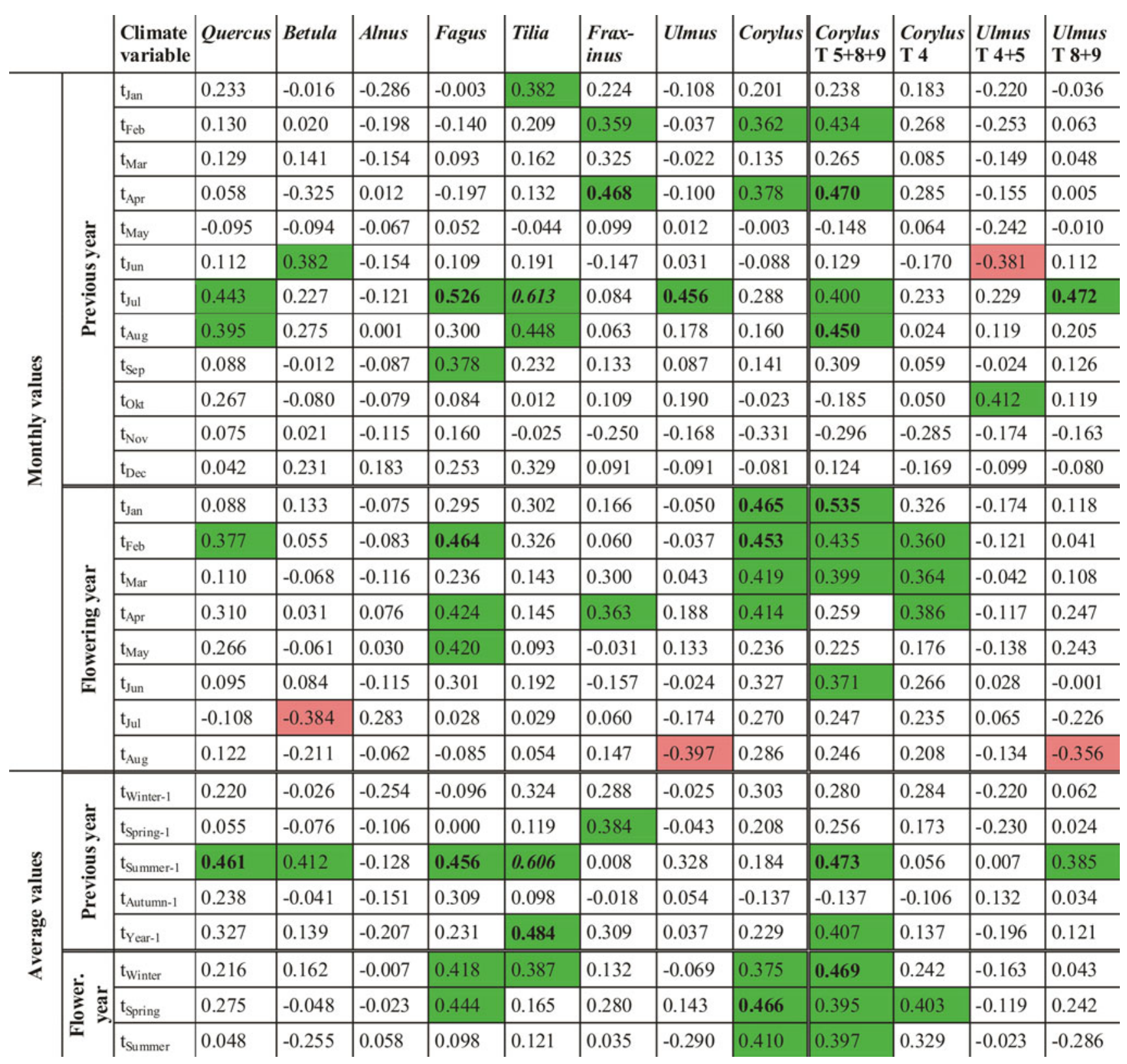

Average PAR of all four traps were used where not otherwise stated; green shading indicates significant $(P<0.05)$ positive correlations, red shading significant negative correlations. Where $P<0.01$ and $P<0.001$, values are shown in bold and bold italic respectively

\section{Results}

The time series of log transformed pollen accumulation rates for the eight species are shown in Fig. 2. The total pollen accumulation including both herbs and trees for the period 1986-2002 in the four traps ranged from 12,800 to 59,600 grains cm $^{-2}$ year $^{-1}$ with an average of 33,900 grains $\mathrm{cm}^{-2}$ year ${ }^{-1}$. For the sum of the eight main tree species the range in the four traps was 9,100-50,300 pollen grains, and they make up $45-81 \%$ of the total pollen influx. The amount of herb pollen may be biased through transport by insects that are often found in the pollen traps.

\section{Correlation analysis}

With the exception of Ulmus and Corylus, the PAR of each species in each of the four traps was significantly correlated with that in the other traps. For Ulmus, traps 4 and 5 as well 
Table 2 Correlation coefficients between log annual PAR and total monthly and seasonal precipitation of the flowering year and the year before

\begin{tabular}{|c|c|c|c|c|c|c|c|c|c|c|c|c|c|c|}
\hline & & $\begin{array}{l}\text { Climate } \\
\text { variable }\end{array}$ & Quercus & Betula & Alnus & Fagus & Tilia & $\begin{array}{l}\text { Frax- } \\
\text { inus }\end{array}$ & Ulmus & Corylus & $\begin{array}{l}\text { Corylus } \\
\text { T } 5+8+9\end{array}$ & $\begin{array}{l}\text { Corylus } \\
\text { T } 4\end{array}$ & $\begin{array}{l}\text { Ulmus } \\
\text { T } 4+5\end{array}$ & $\begin{array}{l}\text { Ulmus } \\
\text { T 8+9 }\end{array}$ \\
\hline \multirow{20}{*}{ 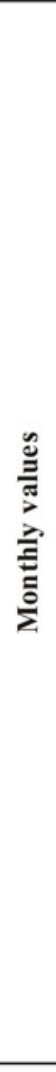 } & \multirow{12}{*}{ 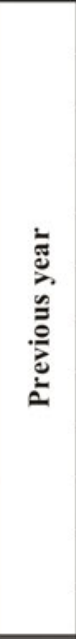 } & $\mathrm{p}_{\text {Jan-1}}$ & -0.154 & -0.134 & -0.174 & -0.142 & 0.061 & 0.084 & 0.030 & -0.026 & -0.059 & 0.016 & 0.109 & 0.048 \\
\hline & & $\mathrm{p}_{\mathrm{Feb}-1}$ & 0.190 & -0.002 & -0.006 & 0.095 & 0.146 & 0.192 & 0.024 & 0.363 & 0.441 & 0.311 & 0.041 & 0.034 \\
\hline & & $\mathrm{p}_{\text {Mar-1 }}$ & 0.201 & 0.079 & -0.152 & 0.364 & -0.043 & 0.039 & 0.110 & -0.063 & -0.144 & -0.011 & 0.026 & 0.076 \\
\hline & & $\mathrm{p}_{\text {Apr-1 }}$ & 0.296 & 0.508 & -0.050 & 0.200 & 0.066 & -0.340 & 0.330 & 0.077 & 0.016 & 0.064 & 0.041 & 0.369 \\
\hline & & $\mathrm{p}_{\text {May-1 }}$ & 0.049 & 0.073 & -0.213 & -0.104 & 0.176 & -0.068 & 0.211 & -0.135 & 0.023 & -0.170 & 0.245 & 0.114 \\
\hline & & $\mathrm{p}_{\text {Jun-1 }}$ & -0.204 & -0.438 & 0.036 & -0.131 & -0.372 & 0.010 & 0.042 & -0.009 & -0.018 & -0.020 & 0.209 & 0.051 \\
\hline & & $\mathrm{p}_{\text {Jul-1 }}$ & -0.250 & -0.124 & -0.022 & -0.002 & -0.099 & 0.120 & -0.109 & 0.205 & 0.091 & 0.177 & -0.116 & -0.069 \\
\hline & & $\mathrm{p}_{\text {Aug-1 }}$ & -0.142 & 0.040 & 0.358 & 0.511 & 0.109 & 0.272 & 0.363 & 0.099 & 0.060 & 0.125 & 0.002 & 0.311 \\
\hline & & $\mathrm{p}_{\text {Sep-1 }}$ & 0.026 & 0.084 & -0.034 & -0.052 & 0.138 & 0.082 & -0.290 & 0.158 & 0.066 & 0.135 & -0.200 & -0.165 \\
\hline & & $\mathrm{p}_{\mathrm{Okt}-1}$ & -0.156 & -0.545 & -0.012 & -0.070 & -0.377 & 0.104 & 0.010 & -0.014 & -0.283 & 0.036 & -0.120 & 0.034 \\
\hline & & $\mathrm{p}_{\text {Nov-1 }}$ & -0.211 & 0.092 & 0.134 & -0.190 & -0.140 & -0.421 & -0.297 & -0.210 & -0.095 & -0.232 & -0.359 & -0.301 \\
\hline & & $\mathrm{p}_{\text {Dec-1 }}$ & -0.413 & -0.006 & 0.001 & 0.215 & -0.108 & 0.160 & -0.116 & -0.139 & -0.099 & -0.152 & -0.047 & -0.070 \\
\hline & \multirow{8}{*}{ 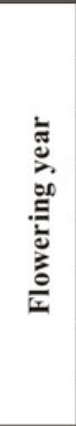 } & $\mathrm{p}_{\mathrm{Jan}}$ & -0.066 & 0.011 & -0.026 & 0.058 & 0.136 & -0.016 & 0.053 & 0.210 & 0.147 & 0.182 & -0.182 & 0.142 \\
\hline & & $\mathrm{p}_{\mathrm{Feb}}$ & 0.365 & -0.333 & -0.091 & 0.142 & 0.040 & 0.113 & 0.169 & 0.620 & 0.361 & 0.612 & 0.082 & 0.286 \\
\hline & & $\mathrm{p}_{\mathrm{Mar}}$ & -0.042 & -0.318 & -0.026 & 0.024 & -0.151 & 0.123 & 0.231 & 0.238 & 0.047 & 0.263 & 0.322 & 0.255 \\
\hline & & $\mathrm{p}_{\text {Apr }}$ & 0.001 & -0.160 & -0.251 & 0.132 & 0.119 & 0.310 & -0.238 & -0.015 & 0.025 & -0.040 & -0.084 & -0.214 \\
\hline & & $\mathrm{p}_{\text {May }}$ & -0.254 & -0.104 & 0.196 & 0.324 & -0.030 & 0.243 & 0.178 & -0.130 & -0.032 & -0.157 & 0.237 & 0.162 \\
\hline & & $\mathrm{p}_{\text {Jun }}$ & 0.003 & -0.411 & -0.261 & -0.119 & -0.473 & -0.049 & 0.002 & -0.011 & -0.337 & 0.068 & 0.097 & -0.039 \\
\hline & & $\mathrm{p}_{\text {Jul }}$ & 0.128 & 0.100 & -0.012 & 0.031 & -0.138 & -0.099 & 0.209 & 0.346 & 0.127 & 0.339 & -0.058 & 0.269 \\
\hline & & & -0.248 & & 0.102 & & -0.469 & & & -0.093 & & & -0.106 & -0.107 \\
\hline \multirow{8}{*}{ 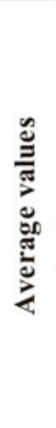 } & \multirow{5}{*}{ 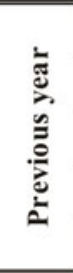 } & $\mathrm{p}_{\text {Winter-1 }}$ & 0.065 & -0.324 & -0.104 & -0.073 & 0.090 & 0.155 & 0.086 & 0.126 & 0.114 & 0.137 & 0.166 & 0.108 \\
\hline & & $\mathrm{p}_{\text {Spring-1 }}$ & 0.252 & 0.279 & -0.226 & 0.216 & 0.104 & -0.147 & 0.309 & -0.083 & -0.060 & -0.080 & 0.172 & 0.248 \\
\hline & & $\mathrm{p}_{\text {Summer-1 }}$ & -0.303 & -0.247 & 0.207 & 0.224 & -0.164 & 0.219 & 0.168 & 0.155 & 0.071 & 0.151 & 0.041 & 0.163 \\
\hline & & $\mathrm{p}_{\text {Autumn-1}}$ & -0.201 & -0.259 & 0.041 & -0.186 & -0.233 & -0.100 & -0.356 & -0.012 & -0.196 & -0.006 & -0.415 & -0.255 \\
\hline & & $\mathrm{p}_{\text {Year-1 }}$ & -0.239 & -0.162 & -0.008 & 0.137 & -0.132 & 0.094 & 0.008 & 0.063 & -0.034 & 0.062 & -0.092 & 0.047 \\
\hline & \multirow{3}{*}{ 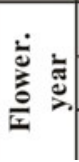 } & pwinter & -0.104 & -0.156 & -0.056 & 0.224 & 0.025 & 0.140 & 0.039 & 0.321 & 0.189 & 0.295 & -0.083 & 0.168 \\
\hline & & $\mathrm{p}_{\text {Spring }}$ & -0.165 & -0.287 & 0.002 & 0.246 & -0.051 & 0.320 & 0.132 & 0.047 & 0.016 & 0.035 & 0.272 & 0.145 \\
\hline & & $\mathrm{p}_{\text {Summer }}$ & -0.069 & -0.302 & -0.073 & -0.103 & -0.548 & -0.170 & 0.060 & 0.119 & -0.219 & 0.203 & -0.041 & 0.060 \\
\hline
\end{tabular}

Average PAR of all four traps were used where not otherwise stated; green shading indicates significant $(P<0.05)$ positive correlations, red shading significant negative correlations. Where $P<0.01$ and $P<0.001$, values are shown in bold and bold italic respectively

as traps 8 and 9 were correlated with each other, but there was no correlation between the two groups. The correlation between traps 8 and 9 is mainly determined by the values for 1993, where Ulmus PAR was unusually high in both traps. The removal of this year results in no correlation between these two traps. For Corylus, the annual PAR in trap 4 was not correlated with any of the other traps, whereas the other traps were all correlated with each other.

Significant correlations between pollen deposition and at least one climate variable were found for all taxa. While most of the significant correlations with temperature were positive, both positive and negative correlations were found with precipitation (Tables 1,2).

Mostly, seasonal average temperatures resulted in significant correlations only where one or more individual months within the period were also significant. Thus summer temperatures of the previous year have a significant effect on pollen deposition of several species, but different taxa show significant correlations with different months. This includes July for Fagus and Ulmus, July and 

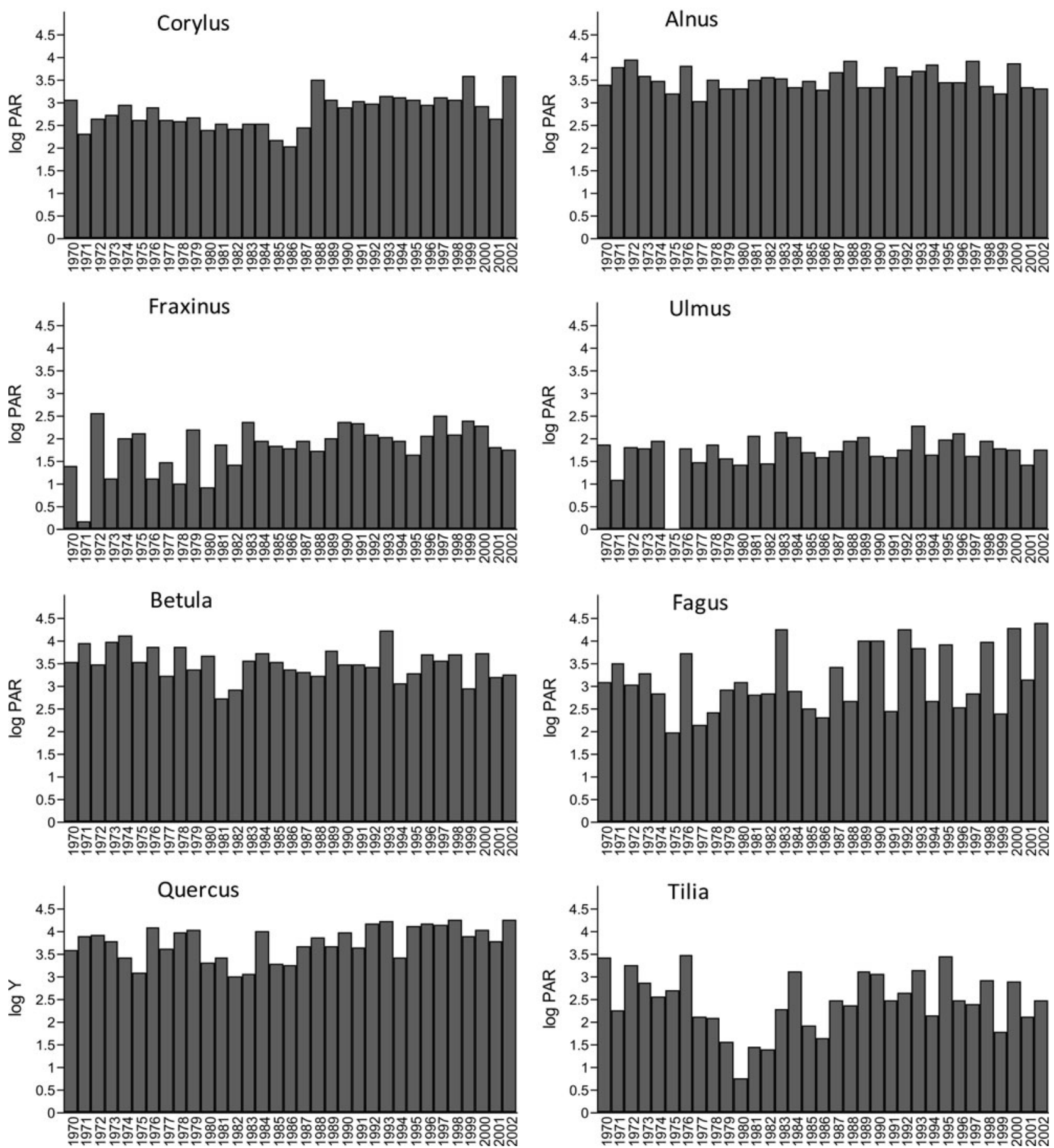

Fig. 2 Annual average log PAR in the four pollen traps for the eight most common tree species during the period 1970-2002

August for Quercus and Tilia and June for Betula. Winter and spring temperatures in the year of flowering also have a positive effect on PAR for several species. The only significant correlations with annual values were the positive correlation between annual mean temperature and PAR of Tilia and of Corylus in traps $5+8+9$ in the following year. There are few negative correlations between PAR and temperature, most of which are for months after the end of the flowering season (July for Betula and August for Ulmus). These results are probably spurious. Significant negative correlations with precipitation are more common than with temperature. Precipitation in winter or spring months of the year before flowering has a significant positive effect on Betula, Fagus and Corylus pollen 
deposition. Precipitation in August positively affects PAR of Alnus, Fagus and Ulmus in the following year, while precipitation in different autumn months has a negative effect on several species. During the flowering year, February precipitation was positively correlated with Quercus and Corylus PAR, while rain during the flowering season had negative effects on Betula and Tilia.

Using the individual trap data for Corylus, we find that PAR from traps $5+8+9$ partly responds to different monthly values than PAR from trap 4 . The three traps respond to spring and summer temperatures of the year before flowering, while trap 4 is most strongly affected by precipitation in February of the flowering year.

The annual average PAR for Ulmus pollen over the four traps is positively correlated with temperature in July and precipitation in August of the previous year. Separating the pollen traps into two groups shows a negative correlation with June temperature and autumn precipitation and a positive relationship with October temperature of the previous year for traps $4+5$, while there is a positive correlation with previous year July temperature and April precipitation for the combination of traps $8+9$, which receive only long-distance transported Ulmus pollen.

The winter index of the NAO of the flowering year was found to positively correlated to log PAR for Fagus $(r=0.482, P<0.01$ ), which fits with the species positive correlation to winter temperatures. No other significant relationships to the winter NAO index were found.

\section{Linear models}

Table 3 shows the climate parameters included, the degrees of freedom and the adjusted $R$-squared for the optimal models selected using the Bayesian Information Criterion (BIC) for each pollen type. Most parameters included in the optimal model have significant unique effects on PAR, as indicated by the significance levels. Some parameters, which did not themselves have significant effects, however interact with other parameters, increasing their effect. If this increase is sufficiently large (as measured by the BIC) such variables are also included in the optimal model.

As with the correlation analysis, the multiple linear regression analysis for Corylus showed the difference between trap 4 and the other traps. Only precipitation in February of the flowering year was included in the optimal model for trap 4, while the optimal model for traps $5+8+9$ incorporated many variables from both the previous and flowering year. There were also differences between the two groups of traps for Ulmus. The Ulmus PAR in traps $8+9$, which receive only long-distancetransported pollen, are most strongly affected by previous July temperature and by temperature and precipitation in April, whereas traps $4+5$, where some Ulmus occurs in
Table 3 Statistical parameters of the optimal linear model selected using BIC for each pollen type

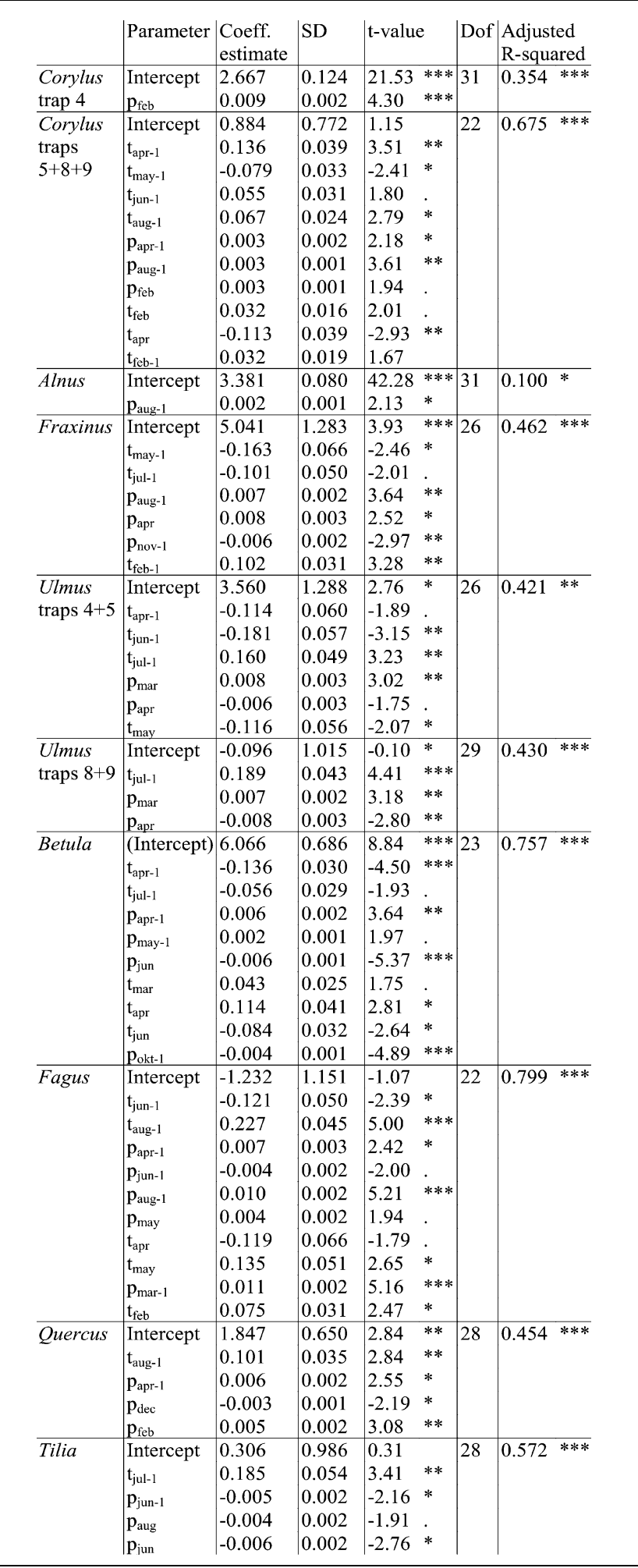

Except where indicated, models were fitted using average PAR in all four traps. SD: Standard deviation of the coefficient estimates. Dof: Degrees of freedom of the optimal model. Significance levels of parameters and models are indicated: $* P<0.05$; ** $P<0.01$; *** $P<0.001$ 
the forest section are affected by a wider range of climatic variables, including April, June and July temperatures of the previous year as well as March and April precipitation and May temperature of the flowering year. However, both sets of traps show a positive relationship with a high regression slope to July temperature of the previous year, indicating that this variable is important for Ulmus PAR, although it was not significantly correlated to Ulmus PAR in traps 4 and 5, when other variables were not taken into account.

For Fagus, the optimal linear model includes many monthly climate variables, some of which were also individually correlated with pollen accumulation, and the model has very high $R$-squared value, indicating that each of the parameters have both marginal and unique effects on PAR, and together explain $80 \%$ of the observed variation. One of the most important factors, judging from regression slope and significance appears to be the temperature of August in the previous year, while the correlation analysis indicated that July and September temperatures were more important.

For Alnus, only the August precipitation of the previous year is included in the optimal linear model, which explains just $10 \%$ of the variation observed in Alnus PAR. The optimal linear model for Quercus pollen accumulation includes August temperature, April and December precipitation (negative effect) of the previous year as well as February precipitation of the flowering year. The effects of previous July and current February temperature seen in the correlation analysis are not included, probably because these climatic variables are quite strongly correlated with August temperature and February precipitation respectively, reducing their unique effects on Quercus pollen accumulation.

Time series analysis

Spectral analysis was carried out for each species on the average pollen accumulation rates in all four traps and on individual traps, to detect if the pollen accumulation of the different tree species showed any cyclic patterns. The average pollen accumulation for Alnus generated a marked peak with high power in the Lomb periodogram at frequency 0.33 (corresponding to a 3 -year cycle), although the Monte Carlo permutation test indicated that this peak was not statistically significant (Fig. 3). To test if the lack of significance was a result of a too short sampling period, the pollen record for Alnus was doubled, and then the peak at frequency 0.33 became significant at the $95 \%$ level. This indicates that if pollen monitoring were to be carried on for 66 years, and if Alnus pollen accumulation continued to show a similar pattern of variation, it would have significant 3-year cyclicity, even though this pattern is not

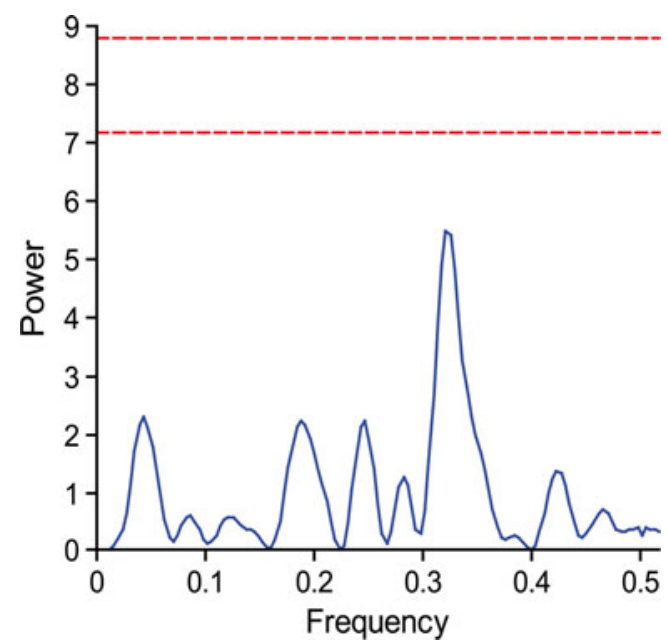

Fig. 3 Spectral analysis of PAR of Alnus glutinosa (all four traps); the dashed red lines show the 95 and $99 \%$ confidence limits resulting from a Monte Carlo permutation test

significant in the current time series. None of the other species showed significant peaks the periodogram for either the actual sampling series or the doubled series. If the sampling series were to be tripled to 99 years, there were peaks for Betula at frequency 0.45 (a 2.2 year cycle), Tilia at frequency 0.036 (a 2.7 year cycle) and Fraxinus at 0.12 (an 8.2 year cycle).

Autocorrelation analysis likewise showed a lack of regular cyclicity in the pollen accumulation rates, as no significant correlations were found for any species in the 33-year data series, regardless of the time lag used (Fig. 4). Again, Alnus shows the most interesting pattern, in that it has marked, if non-significant positive relationships at 3,6, 9,12 and 15 year time lags, indicating a tendency towards 3-year cyclicity. It is also worth noting, that except for Quercus all species show a slight negative relationship at a 1 year time lag. This could be due to a tendency of very high flowering years to be followed by low flowering years.

\section{Discussion}

For most of the species in this study, annual pollen accumulation rates in the four traps were strongly correlated, and responded similarly to the climatic conditions. For Corylus and Ulmus however, some traps showed a different pattern of annual variation from the others, and different responses to some climatic variables. For these species, it made a difference whether or not the species in question occurred in the forest near the traps. Some Ulmus trees were present in the Carlsberg enclosure locally, but not in the Lime enclosure where traps 8 and 9 are located, so the Ulmus pollen in these traps must be long-distance transported. The cover of Corylus is higher near trap 4 than the 

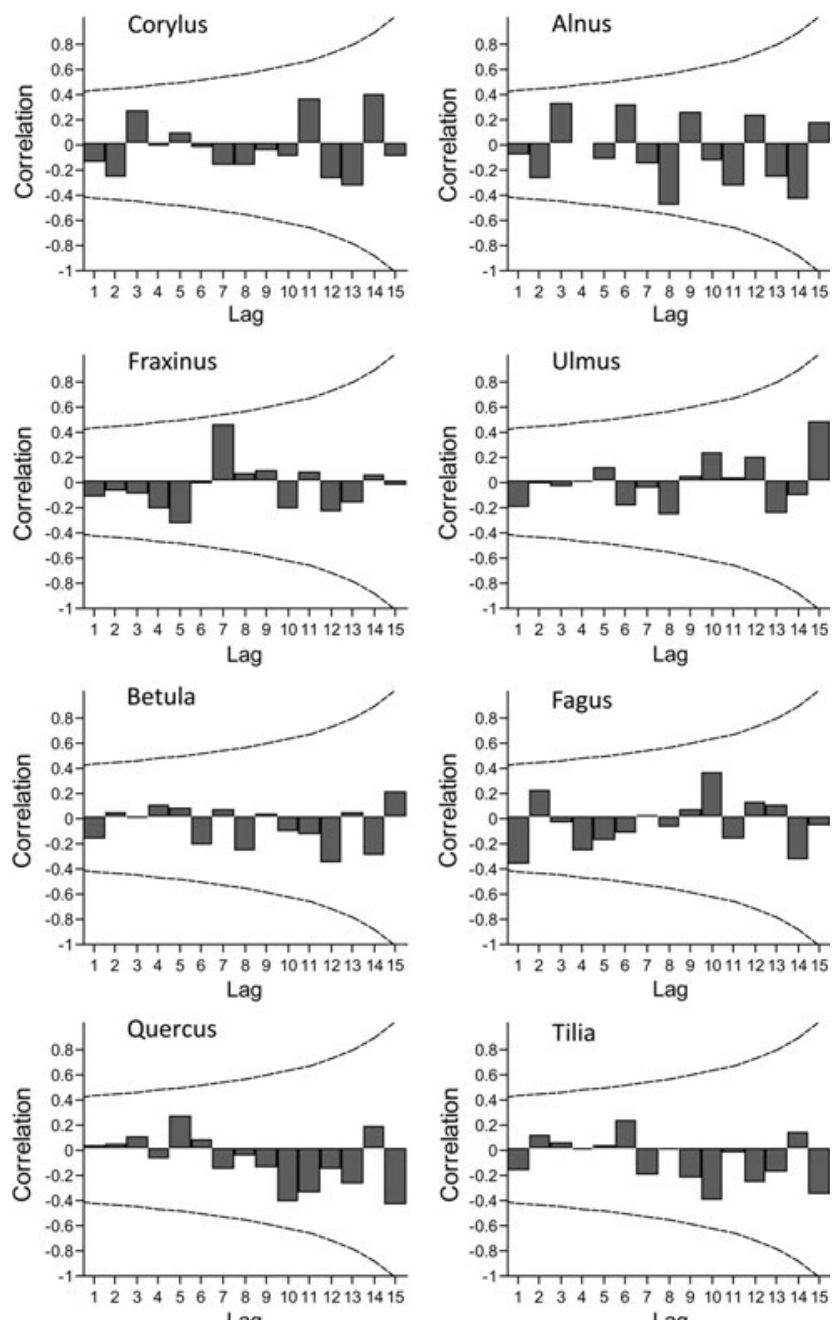

Lag

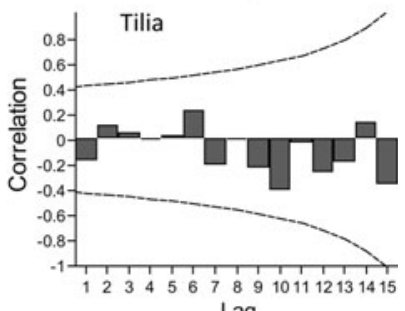

Lag

Fig. 4 Autocorrelation diagrams for PAR of each species at time lags of $0-15$ years; the curved lines show the $5 \%$ significance level

other traps, which is reflected not only in higher Corylus PAR in this trap, but also in a different pattern of correlations. This indicates that individual trees may differ in their inter-annual pollen production from neighbouring trees of the same species. This individualistic variability in pollen production also emerged from the analyses of Fagus pollen deposition in different European forests (Pidek et al. 2010, this volume). However, we also show that the pollen production of many trees of a species in one forest did respond to variability in temperature and precipitation. Thus, individualistic variation for most of the trees seems to be harmonized by climate. Still, local filtering or re-deposition effects may significantly influence individual traps, especially if they are placed under the canopy. Therefore it can be risky to draw conclusions about the influence of climatic factors on the flowering of different species from studies using single pollen traps near the pollen releasing taxon in question.
Effect of temperatures in the year before flowering

In this study, we saw that for several species: Betula, Quercus, Fagus, Tilia and Ulmus pollen productivity is positively correlated with summer temperatures of the previous year. This was also true for Corylus, with the exception of trap 4 . The months with the strongest correlations likely reflect the time when the flowers of the species are differentiated. For example Fagus flowers are differentiated later in the summer compared to Betula flowers (Andersen 1974) and this is clearly seen in the different monthly temperature with significant correlation (Table 2).

Andersen (1980) observed positive correlations between summer temperatures and Fagus and Quercus pollen percentages. Similar positive effects of summer temperatures on PAR were observed for Fagus in areas of Poland, the Czech mountains and Georgia (van der Knaap et al. 2010, this volume). Holmsgaard and Olsen (1960) found increased flowering and seed set in Fagus following warm, dry conditions in June and July of the previous year, and several other studies have reported similar relationships (Harmer 1994). For Betula, Rasmussen (2001, 2002) also found a positive correlation between the seasonal amount of pollen and the temperature of the previous summer (May to August) and a weaker negative correlation with precipitation in the same period. In Southern Sweden, Dahl and Strandhede (1996) found a positive effect of temperature of the previous May to July and in northern Finland Betula pollen emissions are correlated with June temperature of the previous year (Autio and Hicks 2004; Hicks 2006).

\section{Effect of temperatures in flowering year}

Winter temperatures in the flowering year are positively related to PAR of Fagus, Tilia, Quercus (only February) and Corylus except in trap 4, and spring temperatures were positively correlated with Fagus, Corylus and Fraxinus (only April). The positive relationship between Fagus PAR and winter NAO index is probably due to the effect of the NAO on winter and spring temperatures in Denmark.

After cold winters (which are typically also long), the flowering season of Corylus starts later than usual (Rasmussen 2001) and some Corylus flowers may be damaged by late frost (Sommer and Rasmussen 2008). The latter also applies Fagus (Innes 1994) and may apply to Quercus and Tilia as well. Positive correlations with winter or spring temperatures have been observed for Quercus in Poland and the Czech mountains (van der Knaap et al. 2010, this volume). For Fagus, this effect was not seen in the study regions of van der Knaap et al. (2010, this volume), probably because these areas were much further south of the northern limit of Fagus. Sommer and 
Rasmussen (2008) suggest that Alnus and Ulmus may be sensitive to frost damage, but we found no correlations with winter and spring temperature in Draved Forest for these species to support this suggestion, nor were such correlations found in other regions (van der Knaap et al. 2010, this volume).

The negative relationships between Betula and Ulmus and flowering year July and August temperatures are difficult to explain, as these occur after the flowering seasons. The temperature earlier in the flowering year seems from the correlation analysis to have little effect on Betula flowering, although March, April and June temperatures are selected in the linear model in combination with a range of other factors. Compared to climate variables of the flowering year, summer temperatures of the previous year have an overriding effect on the release of Betula pollen (Rasmussen 2001, 2002; Dahl and Strandhede 1996).

The timing of the flowering season for individual species varies from year to year, depending on weather conditions (Sommer and Rasmussen 2008), and this may partly confound the relationship between pollen accumulation rates and climate conditions in individual months in the flowering year, as a given calendar month may in some years cover a larger or smaller proportion of the flowering season of a given plant species. Van der Knaap et al. (2010, this volume) analysed correlations between PAR and climate variables that were averaged over multiple months, which can solve the problem of changes in flowering season. They found that many relationships persisted for periods of several months. In the present study, we also found some correlations that persisted for longer periods, such as that for Fagus and Corylus PAR with winter and spring temperatures. However, we also found many correlations with single month variables that did not extend to following months. In Finland, both Betula and Pinus pollen have been shown to be strongly related to July temperature, and even shorter time spans have been shown to give good correlations there (Autio and Hicks 2004). It may be that the relationship between PAR and climate is more restricted to short time spans in the North, where growing season is very short, than it is further south in Europe.

In this study, the effects found of temperature on PAR were almost all positive. This is in contrast to the findings of van der Knaap et al. (2010, this volume) where the effect of temperature was also often negative. Low winter temperatures were observed to result in higher PAR for Fagus and Betula in Poland, whereas lower summer temperatures benefitted Alnus in some of the sites in the Czech mountains and Tilia in Georgia (van der Knaap et al. 2010, this volume). As far as winter temperatures are concerned, a main difference is probably the oceanic climate in Denmark compared to Poland, where cold winters are more common, and the trees may be more adapted to this.
A positive response to cool summers is probably related to limitations in water availability (van der Knaap et al. 2010, this volume), which is less of a problem in Draved Forest, with its more oceanic climate with relatively high rainfall and cool summers. However, the lowland position of Draved Forest in the landscape means that the groundwater table is near the surface, and the trees consequently have shallow root systems. This can make them susceptible to drought.

\section{Effects of precipitation}

The patterns of correlation with precipitation are less clear than with temperature. This could be partly due to the higher degree of spatial heterogeneity in precipitation data, although this should not be too pronounced in South Jutland. Our results show that Betula pollen production is positively correlated to precipitation in April of the year before flowering, Alnus, Fagus and Ulmus to precipitation in August of the previous year, and Corylus pollen production to precipitation in February of the year before flowering. Drought at the time of flower formation probably limits the amounts of flowers that can successfully form and produce pollen, and later in the summer may result in the death of already formed buds. However, too much water in the year before flowering can also have negative effects, as seen for Betula and Tilia with respect to June precipitation. Several species respond negatively to precipitation during autumn months. This has also been observed Fagus, Quercus and Betula in the Czech mountains (van der Knaap et al. 2010, this volume). Andersen (1980) found a negative correlation between precipitation in April of the previous year and Betula and Alnus pollen percentages for the first 10 years of pollen trapping. For Alnus, this pattern could not be found in the longer time series, and for Betula the new results show the opposite trend. This underlines the importance of long records for drawing conclusions about pollen-climate relationships.

Precipitation during the flowering year can have a positive effect on pollen accumulation, as seen for Quercus and Corylus with respect to February precipitation, or a negative effect as seen for Betula and Tilia. As with temperature, there may be relationships which we cannot detect because of annual variations in flowering time. That precipitation during the flowering season can have a direct negative effect on pollen release and dispersal is known from pollen monitoring stations, where the daily observations of pollen concentration in the atmosphere show a clear negative relationship to precipitation, as rain washes the pollen out of the atmosphere (Sommer and Rasmussen 2008). That this can also affect the total pollen accumulation over the year is seen for Betula, which has a negative correlation with June precipitation and for Tilia, where 
pollen deposition is negatively correlated with June, August and total summer precipitation in the flowering year. Holmsgaard and Olsen (1960) found that heavy rain in April had a negative effect on Fagus fruit setting, but we did not observe a similar effect on pollen production.

For Corylus, pollen deposition is correlated with precipitation in February and in July of the flowering year. Emberlin et al. (2007) found that rainfall had no impact on the start date of the pollen season for Corylus in England, but in Draved February rain seems to favour pollen dispersal. The correlation to July precipitation, which occurs after the flowering season, is most probably spurious. One possible explanation for a correlation with precipitation after the flowering season could be that heavy rain washes pollen deposited on branches and leaves into the traps. This could be supported by the fact that the relationship seems to be strongest for trap 4, as this trap is situated right next to a Corylus shrub, with overhanging branches, from which pollen could be washed straight into the trap.

\section{Combined climate effects}

Multiple linear regression models showed that combinations of climate variables can in some cases affect PAR where simple correlation did not show any link. For example for Ulmus pollen in traps $4+5$ the linear modelling revealed a relationship to a combination of precipitation and temperature variables during the previous year and the flowering season, of which only June temperature showed a significant correlations on its own, while for traps $8+9$, the model included in addition to previous July temperature the combination of temperature and precipitation during April of the flowering year.

The Betula pollen accumulation in Draved Forest is positively related with the summer temperatures (especially in June) of the previous year, and negatively correlated with June precipitation of the previous year (which is itself negatively related to June temperature). In addition to this there was also a negative correlation with precipitation in the flowering season, which indicates a direct effect of the current weather conditions on pollen release and dispersal. This combination has also been observed in other studies. In 1993, which had by far the highest Betula PAR in the Draved traps, an exceptionally high amount of Betula pollen was also observed at the monitoring stations in Denmark (Rasmussen 2001) and southern Sweden (Dahl and Strandhede 1996). Rasmussen (2001) suggests the combination of a warm, dry summer in 1992, followed by a very mild winter and favourable weather during the flowering season as explanation for this high accumulation, which fits well with our findings. The low pollen production of Betula in the previous year, 1992, may also have played a role (Dahl and Strandhede 1996).
Non-climatic effects

For Corylus and Alnus, the relationship between climate and PAR may be partly confounded by the fact that the traps were sometimes collected after the beginning of the flowering season. This should not affect the other, later flowering species.

The pollen production of Alnus in Draved Forest is only weakly related to the climate of either the previous or current year, with the only significant correlation being to August precipitation, which explains about $10 \%$ of the observed variation. In Poland and the Czech mountains, van der Knaap et al. (2010, this volume) found that the relationship of Alnus glutinosa-type PAR to climate varied markedly between study regions, depending on the placement in the landscape. As for Corylus, some relationships to climate may be overlooked in Draved Forest because of late sampling in some years. However, the time series analysis indicates that there may be 3 -year cyclicity in the Alnus values, although the time series is not yet long enough to establish this as statistically significant. If the Alnus trees are in fact only able to produce large amounts of pollen every third year, this may explain the lack of strong correlation with climate variables. Andersen (1980) suggested, although for Betula, that only years which do not follow a high productivity year may be expected to reflect climate conditions. However, removing years following particularly high Alnus pollen accumulations (1973, 1977, 1989, 1992, 1994, 1995, 1998 and 2001) from the analysis did not improve the relationship to the climatic variables. McVean (1955) studied flower formation in $\mathrm{Al}$ nus glutinosa and also found no simple relationship with climatic factors such as temperature and sunshine. Catkins are initiated in early July (McVean 1955), so a relationship with for example temperature before that time could be expected but was not found. During the flowering year, Alnus pollen is released very early, in February and March (McVean 1955) and sometimes as early as January (Sommer and Rasmussen 2008). Cold winter weather may delay the onset of flowering (Rasmussen 2001), but does not seem to affect the overall pollen production.

Thus, it seems that the pollen production of Alnus may be more controlled by internal biological factors than by temperature and precipitation. However, annual Alnus pollen accumulation rates in the individual traps are correlated with each other, indicating that at least at forest scale there are external factors that influence the pollen production of the trees, causing them to be synchronised. Changes in the ground water table, which is known to fluctuate markedly in Draved Forest (Møller and Bradshaw 2001), may affect Alnus, which grows on moist soils. In response to gradually wetter conditions as drainage ditches have been closed (Bradshaw et al. 2005), the basal area of 
Alnus in parts of the forest increased during the trapping period (Wolf 2003), but this is not the case in the Carlsberg and Lime enclosures. This, and other biomass changes during the period such as increases in Fagus and Quercus biomass are reflected as slight trends in the pollen trap data (Fig. 2), but they are of smaller magnitude than the year-toyear variability, and as the analyses show, not strong enough to overshadow the climatic signals for these species.

Apart from Alnus, no species showed cyclical patterns in the time series analyses. Andersen (1980) saw a biennial flowering pattern for Betula, Alnus, Quercus and Fagus during the first 10 years of pollen trapping (1967-1976), although even in this time interval the pattern was interrupted one or more times for each of the four species. During the now 33 years long trapping period, it seems that such interruptions are so common that no real pattern can be detected. These interruptions seem to be caused by variations in climate, but other factors, such as insect attacks may also play a role. For example, the Winter Moth (Operophtera brumata) has been observed to attack and defoliate especially Tilia, but also Betula, Quercus and Fraxinus in Draved Forest in certain years.

However, there is a tendency for most species towards a negative (albeit non-significant) correlation between PAR for a given species in years immediately following each other. This may be because a year of very high pollen production is rarely followed by another one, as Andersen (1980) also observed. For example, a high pollen production of Betula in one year can have a negative effect on pollen production the following year (Dahl and Strandhede 1996). One reason for this is that development of inflorescences requires large amounts of stored carbohydrates, which are then not available for leaf expansion and shoot elongation. This can result in fewer and smaller leaves on shoots with many catkins, resulting in less photosynthesis and thus resources for the tree to form flowers for the next year (Dahl and Strandhede 1996). Similar mechanisms may well exist in other species as well. Large seed production in mast years may also limit the amount of resources available for pollen production in following years. However, the results of this study indicate that the influence of climatic factors on pollen productivity is stronger than such internal biological factors for most of the tree species in Draved Forest.

\section{PAR and fossil records}

The total pollen accumulation in the four traps $(12,800$ 59,600 pollen $\mathrm{cm}^{-2}$ year ${ }^{-1}$ ) is of similar magnitude to the influx rates calculated for humus layers in podzol soils in Draved Forest for the period A.D. 1750-1980, which was on average 44,000 pollen $\mathrm{cm}^{-2}$ year $^{-1}$ with distinct fluctuations over short time spans (Aaby 1983). This indicates that PAR derived from traps may be relevant for interpreting subfossil pollen records, especially from forest soil and forest hollow studies, despite the fact that these deposits often have difficult age-depth relationships.

In Finland (Hicks 2006; Huusko and Hicks 2009; Kuoppamaa et al. 2009), Northern Sweden (Barnekow et al. 2007) and the Alps (Kamenik et al. 2009) efforts are made to use PAR from fossil records to reconstruct past climate, specifically summer temperatures. This requires high resolution records with good temporal control, because only near-annual variations in PAR can be expected to reflect variations in temperature or precipitation in the way pollen trap records do. Longer-term variations in PAR do not only depend on changes in pollen production, but also on vegetation dynamics, and while these may in turn reflect climate change they do not necessarily do so in the same way as the short term variations in pollen productivity (van der Knaap et al. 2010, this volume).

However, even with such near-annual records, climate reconstructions using PAR would be difficult for Denmark, as PAR, at least for the different tree species studied here, is never strongly correlated with a single climatic variable, as it can be close to a tree line, where species occur close to their climatic limits. In Denmark, this study and others show that PAR usually depends on combinations of temperature and precipitation at different times of the year.

\section{Conclusions}

The results of this study show that the annual pollen production for most tree species in Draved Forest is determined by a combination of climatic variables during the previous season when flower buds and pollen were formed, and the season when pollen is released and dispersed. Summer temperature of the year before flowering is one of the most important factors, but exactly which month's temperature is most important varies from species to species. The effects of precipitation are even more variable between species, and while most observed effects of temperature are positive, the effects of precipitation can be both positive and negative, depending on species and time of year. Linear modelling shows that combinations of monthly average temperature and monthly precipitation can explain between $10 \%$ (for Alnus) and $80 \%$ (for Fagus) of the inter-annual variability in pollen deposition.

Internal, biological factors in the plants and resource limitations were expected to limit high flowering in consecutive years, but except possibly in Alnus, such effects were apparently much weaker than the effects of temperature and precipitation. No significant cyclicity was detected in the pollen accumulation of the different species. 
It is possible that the time series is still too short to detect cyclicity, even though it is the longest pollen trapping series in existence so far.

For Corylus and Ulmus, impact of local vegetation causes some traps to show different annual variation and a different relationship to climatic variables, underlining the advantage of using multiple traps within a study area.

The pollen accumulation rates observed in the traps are comparable to those calculated for podzol soils in the forest, indicating that the trapping results are also useful for interpreting subfossil records.

Acknowledgements We dedicate this contribution to the memory of Svend Th. Andersen for his outstanding work on the understanding and quantifying of pollen dispersal and pollen vegetation relationships, much of which was carried out in Draved Forest. We gratefully acknowledge Sheila Hicks for her long lasting and inspiring involvement in palaeoecology and especially pollen monitoring. We thank Bent Odgaard, Christian Kamenik and Pim van der Knaap for comments and suggestions which improved the manuscript. Finally, we thank the Carlsberg Foundation, The Danish Research Council and GEUS for financial support of the trapping programme.

Open Access This article is distributed under the terms of the Creative Commons Attribution Noncommercial License which permits any noncommercial use, distribution, and reproduction in any medium, provided the original author(s) and source are credited.

\section{References}

Aaby B (1983) Forest development, soil genesis and human activity illustrated by pollen and hypha analysis of two neighbouring podzols in Draved Forest, Denmark. Geological Survey of Denmark, II. Series 114

Andersen ST (1967) Tree-pollen rain in a mixed deciduous forest in South Jutland (Denmark). Rev Palaeobot Palynol 3:267-275

Andersen ST (1970) The relative pollen productivity and pollen representation of North European trees, and correction factors for tree pollen spectra. Geological Survey of Denmark, II. Series 96

Andersen ST (1973) The differential pollen productivity of trees and its significance for the interpretation of a pollen diagram from a forested region. In: Birks HJB, West RG (eds) Quaternary plant ecology. Blackwell, Oxford, pp 109-115

Andersen ST (1974) Wind conditions and pollen deposition in a mixed deciduous forest. II. Seasonal and annual pollen deposition 1967-1972. Grana 14:64-77

Andersen ST (1980) Influence of climatic variation on pollen season severity in wind-pollinated trees and herbs. Grana 19:47-52

Autio J, Hicks S (2004) Annual variations in pollen deposition and meteorological conditions on the fell Aakenustunturi in northern Finland: potential for using fossil pollen as a climate proxy. Grana 43:31-47

Barnekow L, Loader NJ, Hicks S, Froyd CA, Goslar T (2007) Strong correlation between summer temperature and pollen accumulation rates for Pinus sylvestris, Picea abies and Betula ssp. in a high resolution record from northern Sweden. J Quat Sci 22:653-658

Bradshaw RHW, Wolf A, Møller PF (2005) Long-term succession in a Danish temperate deciduous forest. Ecography 28:157-164
Cappelen J, Laursen EV, Jørgensen PV, Kern-Hansen C (2008) DMI monthly climate data collection 1768-2007, Denmark, The Faroe Islands and Greenland. Danish Meterological Institute, Technical Report 08-04

Dahl A, Strandhede SO (1996) Predicting the intensity of the birch pollen season. Aerobiologia 12:97-106

Emberlin J, Smith M, Close R, Adams-Groom B (2007) Changes in the pollen seasons of the early flowering trees Alnus spp. and Corylus spp. in Worcester, United Kingdom, 1996-2005. Int J Biometeorol 51:181-191

Fox J (2002) An R and S-Plus companion to applied regression. Sage Publications, Thousand Oaks

Frich P, Rosenørn S, Madsen H, Jensen JJ (1997) Observed precipitation in Denmark, 1961-90. Danish Meteorological Institute, Technical Report 97-8

Hammer $\varnothing$, Harper DAT, Ryan PD (2001) PAST: paleontological statistics software package for education and data analysis. Palaeontol Electron 4:1-9

Harmer R (1994) Natural regeneration of broadleaved trees in Britain: II seed production and predation. Forestry 67:275-276

Hicks S (2006) When no pollen does not mean no trees. Veget Hist Archaeobot 15:253-261

Holmsgaard E, Olsen HC (1960) Vejrets indflydelse på bøgens frugtsætning. Statens Forstlige Forsøgsvæsen 26:345-370

Huusko A, Hicks S (2009) Conifer pollen abundance provides a proxy for summer temperature: evidence from the latitudinal forest limit in Finland. J Quat Sci 24:522-528

Innes JL (1994) The occurrence of flowering and fruiting on individual trees over 3 years and their effects on subsequent crown condition. Trees 8:139-150

Institute DanishMeterological (1999) Den Nordatlantiske Svingning-trykvariation med konsekvenser. KlimaNyt 4:3-5

Iversen J (1969) Retrogressive development of a forest ecosystem demonstrated by pollen diagrams from fossil mor. Oikos 12(Suppl):35-49

Kamenik C, van der Knaap WO, van Leeuwen JFN, Goslar T (2009) Pollen/climate calibration based on a near-annual peat sequence from the Swiss Alps. J Quat Sci 24:529-546

Kuoppamaa M, Huusko A, Hicks S (2009) Pinus and Betula pollen accumulation rates from the northern boreal forest as a record of interannual variation in July temperature. J Quat Sci 24:513-521

Laursen EV, Thomsen Sjølin R, Cappelen J (1999) Observed air temperature, humidity, pressure, cloud cover and weather in Denmark-with climatological standard normals, 1961-90, Danish Meterological Institute, Technical Report 99-05

McCarroll D, Jalkanen R, Hicks S, Tuovinen M, Gagen M, Pawellek F, Eckstein D, Schmitt U, Autio J, Heikkinen O (2003) Multiproxy dendroclimatology: a pilot study in northern Finland. Holocene 13:829-838

McVean DN (1955) Ecology of Alnus glutinosa (L.) Gaertn.: I. Fruit formation. J Ecol 43:46-60

Møller PF (2000) Natur og forskning i Draved Skov i fortid, nutid og fremtid. Sønderjysk Månedsskrift 4:81-93

Møller PF, Bradshaw RHW (2001) Draved skov- et dansk forskningsprojekt gennem mere end 50 år. Geologi Nyt fra GEUS 2001/4

Pardoe HS, Giesecke T, van der Knaap WO, Svitavská-Svobodová H, Kvavadze EV, Panajiotidis S, Gerasimidis A, Pidek IA, Zimny M, Święta-Musznicka J, Latałowa M, Noryskiewicz AM, Bozilova E, Tonkov S, Filipova-Marinova MV, van Leeuwen JFN, Kalnina L (2010) Comparing pollen spectra from modified Tauber traps and moss polsters from a selection of European forest types. Veget Hist Archaeobot (this volume)

Perneger TV (1998) What's wrong with Bonferroni adjustments. Br Med J 316:1,236-1238 
Pidek IA, Svitavská-Svobodová H, van der Knaap WO, Noryśkiewicz AM, Filbrandt-Czaja A, Noryśkiewicz B, Latałowa M, Zimny M, Święta-Musznicka J, Bozilova E, Tonkov S, FilipovaMarinova M, Poska A, Giesecke T, Gikov A (2010) Variation in annual pollen accumulation rates of Fagus along a N-S transect in Europe based on pollen traps. Veget Hist Archaeobot (this volume)

Rasmussen A (2001) Birkepollensæsonen i Danmark. Trendanalyser samt modeller for sæsonstart, kulminationsdato og sæsonmængde. Vejret 86:6-16

Rasmussen A (2002) The effects of climate change on the birch pollen season in Denmark. Aerobiologia 18:253-265

Schwarz GE (1978) Estimating the dimension of a model. Ann Stat 6:461-464

Sommer J, Rasmussen A (2008) Pollen- \& Sporemålinger i Danmark. Sæsonen 2008. Astma-Allergi Forbundet and Danmarks Meteorologiske Institut, Copenhagen
Stockmarr J (1971) Tablets with spores used in absolute pollen analysis. Pollen Spores 13:615-621

Tauber H (1974) A static non-overload pollen collector. New Phytol 73:359-369

van der Knaap WO, van Leeuwen JFN, Svitavská-Svobodová H, Pidek IA, Kvavadze E, Chichinadze M, Giesecke T, Kaszewski BM, Oberli F, Kalnina L, Pardoe HS, Tinner W, Ammann B (2010) Annual pollen traps reveal the complexity of climatic control on pollen productivity in Europe and the Caucasus. Veget Hist Archaeobot (this volume)

Wolf A (2003) Tree dynamics in Draved Forest. A long-term study of a temperate deciduous forest in Denmark. The Royal Veterinary and Agricultural University, Frederiksberg 